\title{
Multimodal Response Spectrum Method Analysis of Integral Abutment Curved Box Girder Bridge
}

\author{
LUO Chaozhuan ${ }^{1,2}$
}

1. College of Urban Construction and

Safety Engineering, Shanghai Institute of Technology, Shanghai, China;

2.China Nuclear Power Design Company LTD Shenzhen, China

\author{
PENG Dawen \\ College of Urban Construction and \\ Safety Engineering, \\ Shanghai Institute of Technology, \\ Shanghai, China \\ Pengdw@sit.edu.cn
}

\author{
LIN Zhiping ${ }^{1,2}$ \\ 1. Fujian Provincial Expressway \\ Construction Headquarters, Fuzhou \\ 2. College of Urban Construction and \\ Safety Engineering, Shanghai Institute \\ of Technology, Shanghai, China \\ Lzp@126.com
}

\begin{abstract}
In order to simplify analysis of the dynamic characteristics and seismic response of the integral abutment curved box bridge(IACBB), automatic iteration of the multimode modal response spectrum(MMRS) is realized by APDL language of the structure analysis software ANSYS according to the IACBB's structural characteristics. The realization flow of iterative MMRS in Ansys were presented. and the availability and precision of the iterative MMRS were examined by the time-history analysis. The result shows that 1 ) the iterative MMRS is a efficient simplify method, and can be used as an estimating method of seismic analysis for the bridge. And the method provides a reference for future similar structures. 2) several conclusions of earthquake response are given. The research results are helpful for the knowledge of mechanics property of the type of the bridges.
\end{abstract}

Keywords--bridge engineering; integral abutment; iterative MMRS; curved box bridges

\section{INTRODUCTION}

With the continuous development of China's economic development and infrastructure construction, curved box girder has found wide application in the construction of expressways, urban exchange and fly-over crossing. At the same time, while more importance is attached to durability of girder, integral abutment bridge is much welcomed by engineers of all countries for its special advantages. Integral abutment curved box girder bridge is a new bridge structure derived from integration of the idea of curved box girder and idea of integral abutment girder, an integration of advantages of both, taking into consideration the complexity of bearing performance of non-linear function of earth-structure and bending, shearing and bending-torsion effect. Therefore, despite wide and successful application of integral abutment girder in foreign countries, due to difficulties in precise mathematic modulation of the relation between bridge pile-abutment and surrounding soil mass, integral abutment girder design is lacking in theoretical support and applicable anti-seismic specifications or regulations are insufficient ${ }^{[1,2]}$.

This paper is an analysis on dynamic characteristics of abu- tment cured box girder and on simplified calculation of seismic response, using structure analysis software ANSYS and APDL language for realization of automatic iteration of multimodal response spectrum method, i.e. soil effect is modulated with a linear spring and soil non-linear property is realized through reiterative equivalent linear iteration process. This paper is also a probe into seismic response rules of such girder bridge and a meaningful trial in simplified analysis of integral abutment curved box girder.

\section{Mutimodal Response SPecturum Method}

Integral abutment girder is typical of its integral connection between girder and abutment, whose dynamic performance under effects of temperature and seismic load reflects mutual effects of social-structure. Soil pressure on abutment back wall is distributed in a nonlinear manner and varies with the variation of the amount of depth and abutment displacement; deform of abutment depends on the relative rigidity of abutment, pile foundation, deck slabs and on of pile-side lateral rigidity; and abutment effect is related to deformation in abutment. Similarly, pile foundation deformation also depends on effect of pile-side soil on deformation. Therefore, the effect of soil-structure systemic mutual effect should not be determined by the rule of traditional static balance, and ignoring of soil nonlinearity shall lead to deviation that should not be ignored.

The nonlinear response method of girder structure antiseismic analysis has not found much application and in software spectrum analysis, nonlinearity effect is as a rule not considered. In the light of integral abutment girder characteristics, this paper adopts iterative multimodal response spectrum method in simplified anti-seismic analysis.

Iterative multimodal response spectrum analysis method is decomposing vibration modes of structure kinetic equation and obtaining maximum value of vibration mode response according to response spectrum. In this process, direct iteration in nonlinear equation system method is used to realize soilstructure nonlinear effect (equivalent linearization) ${ }^{[7]}$ and structure response maximum value ${ }^{[8]}$ is obtained from combination of vibration modes.

Fund Project : Supported by Leading Academic Discipline Project of Shanghai Municipal Education Commission, Project Number: J51502 and by the Key Subject of Shanghai Committee of Science (NO. 08230511400) 
In consideration of soil-structure mutual effect, this paper adopts $\mathrm{K}-\Delta / \mathrm{H}$ soil pressure coefficient ${ }^{[7]}$ recommended in American NCHRP report (1991) and nonlinear coefficient curve $p-y^{[8]}$ recommended in American API (1993) is adopted in consideration of pile-side soil response.

The following is an analysis of an integral abutment girder $(3 \times 19.2 \mathrm{~m}$ ) (major parameters in Table 1), adopting ANSYS software in establishing finite-element model (Fig. 1) and COM624P V2.0 ${ }^{[13]}$ program in calculating nonlinear $\mathrm{p}-\mathrm{y}$ curve and in kinetic treatment ${ }^{[10]}$.

The analysis process is as follows:

1) Spectrum analysis method is adopted in calculation of back abutment and pile-side soil displacement value under all effects of seismic load with initial rigidity of model (tangent rigidity corresponding to force-displacement curve before deformation);

2 ) Corresponding secant line rigidity is calculated from combination of the obtained displacement value and $K-\Delta / H$ curve of NCHRP and p-y curve of API.

3) Displacement value of back abutment and pile-side soil is recalculated by entering secant line rigidity (initial rigidity adopted for the first time) into finite-element model.
Repeat step 2 and step 3 until the deviation between the displacement values obtained in the final iteration process and in the previous process satisfies the set requirement. In such a case, the final secant line rigidity is deemed as an equivalent rigidity of soil spring under seismic load and corresponding displacement is deemed as an equivalent displacement.

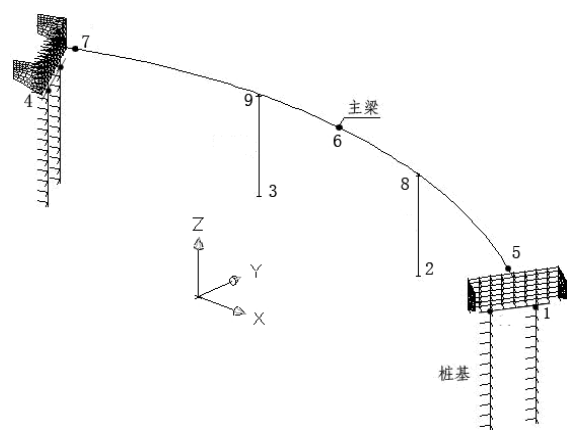

Figure 1. Calculation model scheme

TABLE I. CALCULATION EXAMPLE OF GIRDER PARAMETERS

\begin{tabular}{|c|c|c|c|c|c|c|c|c|}
\hline $\begin{array}{c}\text { Girder } \\
\text { section }\end{array}$ & $\begin{array}{c}\text { Beam section } \\
\text { height (m) }\end{array}$ & $\begin{array}{c}\text { Girder } \\
\text { width (m) }\end{array}$ & $\begin{array}{c}\text { Radius } \\
\text { (m) }\end{array}$ & $\begin{array}{c}\text { Abutment } \\
\text { dimensions(m) }\end{array}$ & $\begin{array}{c}\text { Pile length } \\
\text { (m) }\end{array}$ & $\begin{array}{c}\text { Pier height } \\
\text { (m) }\end{array}$ & $\begin{array}{c}\text { Abutment- } \\
\text { back soil }\end{array}$ & Pile-side soil \\
\hline $\begin{array}{c}\text { single-box } \\
\text { double-cell }\end{array}$ & 1.18 & 9 & 110 & $3 \times 1.5 \times 9$ & 10 & 12 & $\begin{array}{c}\text { dense medium } \\
\text { sand }\end{array}$ & $\begin{array}{c}\text { loose medium } \\
\text { sand }\end{array}$ \\
\hline
\end{tabular}

\section{DYNAMIC BEHAVIOR ANALYSIS}

In calculation of structure seismic response by multimodal response spectrum method, first attention is given to the number of stages of vibration mode to ensure necessary accuracy and to the proportion of respective vibration modes in seismic response. The calculation in this paper illustrates that to 3-span integral abutment curved box girder in the above calculation examples, 15-stage analytical vibration mode is valid for $90 \%$ of mass in terms of calculation.

The analysis in the calculation examples also shows that the maximum transverse, longitudinal and vertical contributions of box girder vibration modes are respectively stage 1 transverse bending, stage 1 horizontal bending and stage 3 vertical bending, their frequencies between that of semi-integral abutment girder and that of rigid frame girder of the same span.

In many cases of light structure and curved girder with single-column pier, transverse rigidity is not necessarily greater than longitudinal rigidity ${ }^{[15]}$, but the mutual effect of concretion of soil-structure and upper and lower structures at abutment increases the longitudinal rigidity of integral abutment girder with pile foundation and results in earlier occurrence of transverse vibration frequency. The calculation in this paper illustrates that in integral abutment curved box girder, purely one-direction vibration mode is nonexistent but that vibration mode in a certain direction might be greater in proportion. This also reflects not only internal force coupling of curved box girder but also mutual coupling of inertia forces $^{[16]}$; girder and abutment integral connection leads to coupling of vibration of upper and lower structures and girder longitudinal displacement is accompanied by vertical bending ${ }^{[17]}$; the asymmetry of NCHRP abutment back soil pressure coefficient curve leads to asymmetric vibration mode of symmetrical structures, particularly in vibration modes including longitudinal vibration.

Analysis of parameters illustrates that in such girder, stage 1 transverse bending vibration and stage 1 longitudinal vibration frequency are most influenced by compactness of abutment back soil and pile-side soil, followed by seismic excitation frequency and girder width and frequency of stage 3 vertical bending vibration as a whole stays intact despite different parameters ${ }^{[14]}$.

\section{RESEARCH ON SEISMIC RESPONSE}

Dynamic time history method provides possibility for consideration of accurate nonlinear mutual effect between foundation and structure. In order to obtain information about accuracy of iterative multimodal response spectrum method seismic response characteristics of such girder under horizontal seismic vibration effect, this paper uses time history method and iterative multimodal response spectrum method in seismic response analysis of a double-column pier' integral abutment curved box girder model ( with major parameters as shown in Table 1) in seismic intensity 8 and site condition II and 
performs comparison between continuous girder models. In order to study the effect of central angle on practicability of multimodal response spectrum method, the analyzed central angle is not limited to $10^{\circ}$ (usually not exceeding $10^{\circ}$ in actual engineering work). To increase comparability between time history analysis result and iterative multimodal response spectrum analysis result, the American El-Centro wave of 1940 (peak value adjustment considered) is selected and El-Centro wave response spectrum is also adopted as acceleration response spectrum.
Due to uncertainty of seismic direction, longitudinal and transverse seismic effects are usually respectively (or simultaneously) taken into consideration. The analysis illustrates that simply longitudinal, simply transverse or spatial combination of seismic motion are approximate to one another in internal force of structural elements in terms of angular bisector symmetry. Therefore, in iterative multimodal analysis method, pier and pile 1, 2, 5, 6 sections can be used for simplified analysis (section position shown in Figure 1).

TABLE II. Iterative Multimodal Analysis Result and Its Relative ERrors （ $\mathrm{A}=0.20 \mathrm{G} ）$

\begin{tabular}{|c|c|c|c|c|c|c|c|c|c|c|c|c|c|c|c|c|c|c|}
\hline \multirow{3}{*}{$\begin{array}{c}\text { Action } \\
\text { direction }\end{array}$} & \multirow{3}{*}{$\begin{array}{c}\text { Section } \\
\text { direction }\end{array}$} & \multicolumn{8}{|c|}{ Pier bottom (pile head) interval force } & \multirow{3}{*}{$\begin{array}{c}\text { Section } \\
\text { position }\end{array}$} & \multicolumn{8}{|c|}{ Girder internal force } \\
\hline & & \multicolumn{2}{|c|}{$\begin{array}{c}\text { Radial shear } \\
\qquad x\end{array}$} & \multicolumn{2}{|c|}{$\begin{array}{c}\text { Tangential } \\
\text { shear Vy }\end{array}$} & \multicolumn{2}{|c|}{$\begin{array}{c}\text { Radial } \\
\text { bending } \\
\text { motion Mx }\end{array}$} & \multicolumn{2}{|c|}{$\begin{array}{c}\text { Tangential } \\
\text { bending } \\
\text { moment My }\end{array}$} & & \multicolumn{2}{|r|}{$a r$} & \multicolumn{2}{|c|}{$\begin{array}{c}\text { Vertical shear } \\
V z\end{array}$} & \multicolumn{2}{|c|}{$\begin{array}{c}\text { In-plane } \\
\text { bending } \\
\text { moment Mx }\end{array}$} & \multicolumn{2}{|c|}{$\begin{array}{c}\text { Out-plane } \\
\text { bending } \\
\text { moment } \\
\mathrm{Mz}\end{array}$} \\
\hline & & $\mathrm{kN}$ & $\%$ & $\mathrm{kN}$ & $\%$ & $\mathrm{kN} \cdot \mathrm{m}$ & $\%$ & $\mathrm{kN} \cdot \mathrm{m}$ & $\%$ & & $\mathrm{kN}$ & $\%$ & $\mathrm{kN}$ & $\%$ & $\mathrm{kN} \cdot \mathrm{m}$ & $\%$ & $\mathrm{kN} \cdot \mathrm{m}$ & $\%$ \\
\hline \multirow{4}{*}{$\begin{array}{c}\text { Longitudi } \\
\text { nal iinal } \\
\text { direction }\end{array}$} & $2_{\mathrm{I}}$ & 2.1 & 5.6 & 50.6 & -8.5 & 513.8 & -3.4 & 11.3 & 5.7 & 5 & 72.9 & 6.4 & 140.7 & -0.1 & 1505.4 & -8.7 & 92.9 & -1.6 \\
\hline & 20 & 2.1 & 7.2 & 50.6 & -8.5 & 513.8 & -3.4 & 11.3 & 6.4 & 6 & 17.2 & 0.7 & 45.0 & 8.1 & 478.1 & -1.6 & 808.1 & 7.4 \\
\hline & $1_{\text {I }}$ & 16.5 & 14.0 & 63.1 & -6.9 & 88.1 & -9.5 & 29.3 & 14.2 & & & & & & & & & \\
\hline & $1_{\mathrm{O}}$ & 16.6 & 12.4 & 65.2 & -2.7 & 91.7 & -5.9 & 29.4 & 12.0 & & & & & & & & & \\
\hline
\end{tabular}

Note: In this table, section position upper script 1 indicates inner side and lower script $\mathrm{O}$ indicate outer pile foundation or pier column

Table 2 lists results and relative errors obtained in iterative multimodal response method analysis on model under longitudinal seismic action with central angle $\theta=10^{\circ}$ (with time history method result as accuracy value). Rules of transverse seismic vibration and simultaneous dual seismic actions are approximately the same.

The analysis illustrates that at central angle $\theta \leq 10^{\circ}$, iterative multimodal response spectrum method result's maximum relative deviation is under $15 \%$ and most of the deviations are within $10 \%$, compared with that of time history analysis result; with the decrease of central angle, maximum deviation tends to decrease (weak variability regulation). This fact tells that iterative multimodal response spectrum method is an effective method in analyzing kinetic behavior of integral abutment curved box girder and great saver of computer hours for its rationality in simplified analysis of seismic response.

In integral abutment girder with pile foundation, piles are the most flexible elements and are subject to transverse displacement due to expansion or retraction of abutment. As abutment rigidity is greater than that of between-span pier rigidity of integral abutment girder, abutment is often assumed to the major bearer of anti-seismic strength.

Figure 2 presents the time history method curve of model pile head displacement with central angle $\theta=60^{\circ}$ under seismic load longitudinal action. The analysis tells that under seismic load action, the displacement of the lower structure of such girder is usually fairly small and as a rule does not result in excessive displacement which leads to destruction, due to controlling strength of internal force. Due to soil spring rigidity decrease in intense earthquake and corresponding decrease in action restraining displacement of structure, other elements of the structure are required to be resistant to such "surplus" displacement, especially piers are expected to posses enough reserved strength to ensure enough resistance to transverse displacement with decreased abutment rigidity in case of intense earthquake.

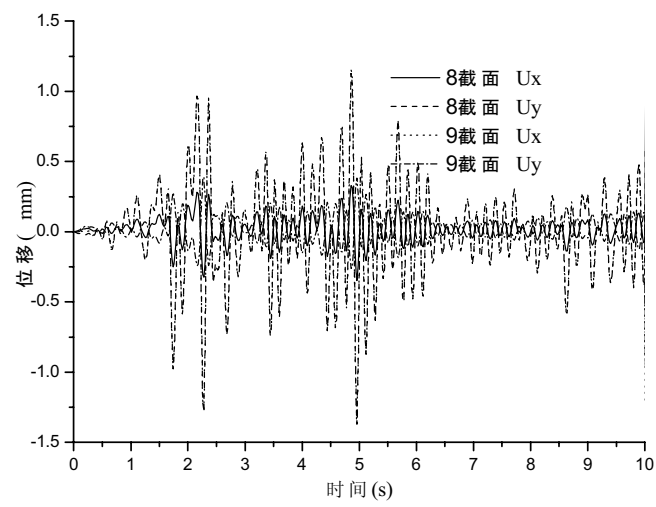

Figure 2. Pile head displacement

Table 3 is the time history analysis result of continuous girder model corresponding to structure illustrated in Figure 1. Due to the strong coupling action in longitudinal and transverse directions of integral abutment curved box girder, under longitudinal (transverse) action, the lower structure tangential (radial) internal force is smaller than that of continuous girder 
of the same span and radial (tangential) internal forces is greater than that of continuous girder.

In the light of girders in the past, major seismic hazards exist in lower structure and failures of the upper structure due to its detriment are rare. Even if in case of upper structure detriment, it is mostly due to detriment of the lower structure and excessive displacement, especially in case of girder bridges and continuous arch bridges ${ }^{[} 19$. Due to integral connection of abutment and beam of integral abutment girder, the entire bridge is under seismic action and horizontal seismic action shall be transmitted to girder with upper structure internal force much greater than $t$ hat of continuous bridges, it is necessary to take into design consideration horizontal seismic action on girder internal force.

TABLE III. CONTINUOUS Girder MOdEl RESUlt $\quad(\mathrm{A}=0.20 \mathrm{G})$

\begin{tabular}{|c|c|c|c|c|c|c|c|c|c|}
\hline direction & Position & \begin{tabular}{|c|}
$\begin{array}{c}\text { Internal } \\
\text { force }\end{array}$ \\
\end{tabular} & $\mathbf{k N}$ & \begin{tabular}{|c|}
$\begin{array}{c}\text { Internal } \\
\text { force }\end{array}$ \\
\end{tabular} & $\mathbf{k N}$ & \begin{tabular}{|c|}
$\begin{array}{c}\text { Internal } \\
\text { force }\end{array}$ \\
\end{tabular} & $\begin{array}{c}\mathbf{k N} \cdot \\
\mathbf{m}\end{array}$ & \begin{tabular}{|c|}
$\begin{array}{c}\text { Internal } \\
\text { force }\end{array}$ \\
\end{tabular} & $\begin{array}{c}\mathbf{k N} \cdot \\
\mathbf{m}\end{array}$ \\
\hline \multirow{5}{*}{$\begin{array}{c}\text { Longitu- } \\
\text { dinal } \\
\text { direction }\end{array}$} & $2_{\text {I }}$ & $V_{x}$ & 0.5 & $V_{y}$ & 56 & $\mathrm{M}_{\mathrm{x}}$ & 528 & $\mathrm{M}_{\mathrm{y}}$ & 3 \\
\hline & 20 & $\mathrm{~V}$ & 0.5 & $V_{y}$ & 56 & $M_{2}$ & 528 & $\mathrm{M}_{\mathrm{y}}$ & 3 \\
\hline & $3_{I}$ & $V_{x}$ & 0.6 & $V_{y}$ & 56 & $\mathrm{M}_{\mathrm{x}}$ & 528 & $\mathrm{M}_{\mathrm{y}}$ & 3 \\
\hline & $3_{0}$ & $V_{x}$ & 0.6 & $V_{y}$ & 56 & $\mathrm{M}_{\mathrm{x}}$ & 528 & $\mathrm{M}_{\mathrm{y}}$ & 3 \\
\hline & 6 & $V_{x}$ & 0.0 & $V_{z}$ & 0.5 & $\mathrm{M}_{\mathrm{x}}$ & 0.0 & $\mathrm{M}_{\mathrm{z}}$ & 0.5 \\
\hline
\end{tabular}

Note: In this table, section position lower script indicates inner side. O indicates outer side pile foundation or pier column

\section{CONCLUSION}

Analysis in this paper has led to the following conclusions:

1) Automatic iteration of multimodal response spectrum method by means of APDL language of ANSYS is an effective simplified method of integral abutment curved box girder action analysis as a preparation for further seismic response analysis. From detailed regulations of anti-seismic highway design $\left[20^{]}\right.$it is known that integral abutment curved box girder belongs to irregular bridge category $\mathrm{C}$ or $\mathrm{D}$ and iterative multimodal response spectrum method can be adopted as an estimation means under seismic action E1 in the design datum period of such girder bridge.

2) Seismic response analysis illustrates that the whole of integral abutment curved box girder is subject to seismic action and that horizontal seismic action shall be transmitted to girder. Therefore, horizontal seismic action on girder internal force should be considered in design; under seismic action, integral abutment curved box girder's lower structure displacement is relatively low and is mainly controlled by internal force and therefore bridge pier should have enough margin of strength.
3 ) Under seismic longitudinal (transverse) action, tangential (radial) internal force of lower structure of integral abutment curved box girder is less than that of continuous girder whereas radial (tangential) internal force is greater than that of continuous girder, with upper structure internal force much greater than that of continuous girder bridge.

\section{REFERENCES}

[1] LIN Zhi-ping, PENG Da-wen. "State-of-the-Art of Integral Abutment Bridges : Design and Practice". World Bridges, 2005, (4): 13-17, 24.

[2] PENG Da-wen, LIN Zhi-ping, HONG Jin-xiang. "Research and Practice for Jointless Bridges". Journal of Highway (8):53-61.

[3] Susan Faraji, John M. Ting, Daniel S.Crovo, and Helmut Ernst. "Nonlinear Analysis of Integral Bridges: Finite-Element Model". Journal of Geotechnical and Geoenviormental Engineering. 2001,127(5): 454-461.

[4] M. Dicleli, S. Albhaisi, M. Y. Mansour. "Static Soil-Structure Interaction Effects in Seismic-Isolated Bridges". Practice Periodical on Structural Design and Construction, 2005, 10 (1): 22-33.

[5] Fan Li-chu, Li Jian-zhong, Wang Jun-jie, "Seismic Design for Urban Viaduct", Beijing: China Communications Press, 2001.

[6] R. M. Barker, J. M. K. Duncan, K. B. Rojiani, P. S. K. Ooi. and S. G.. Kim. "Manuals for the Design of Bridge Foundation, NCHRP Rep.343". Transportation Research Board, National Research Council, Washington D.C., Dec. 1991.

[7] American Petroleum Institute (API). API RP2A-WSD, "Recommended Practice for Planning, Designing, and Constructing Fixed Offshore Platforms-working Stress Design”. 20th Ed. Washington, D.C., 1993.

[8] Wang, S. T, Reese. L. C. COM624P-Laterally Loaded Pile Analysis for the Microcomputer, Version 2.0. FHWA-SA-91-048, 1993

[9] D. A. Brown, M. W. O’Neill, M. Hoit, M. Mcvay, M. H. El Naggar, S. Chakraborty. "Static and Dynamic Lateral Loading of Pile Groups, NCHRP Rep.461". Transportation Research Board, National Research Council, Washington D.C., 2001.

[10] He Jian, "Study on Seismic Response Reduction and Isolation of Curved Beam Bridge", Shanghai: Tongii University, 2000.

[11] San De-shan, Li Qiao, "Analytical Method of Vibration Analysis for Curved-girder Bridges", Journal of Civil Engineering, 2005, 38(10): 6165.

[12] Peng Da-wen, Wang Xin-hui, Hong Jing-xiang, "Research of Dynamic Characteristics of Jointless Bridges", Earthquake Engineering And Engineering Vibration, 2003, 23(4): 95-99.

[13] Peng Da-wen, Luo Chao-zhuan, Lin Zi-pin, "Research on Dynamic Characteristics of Integral Abutment Curved Box Bridges", Journal of Highway and Transportation Research and Development. 2010,27(2),5459

[14] Fan Li-chu, "Seismic for Bridges", Shanghai, Tongji University Press, 1996.

[15] Ministry of Transport of the People's Republic of China , "Seismic Design Detailed Rules for Highway Bridges" (JTG/T B02-01-2008). Beijing: China Communications Press, 2008 